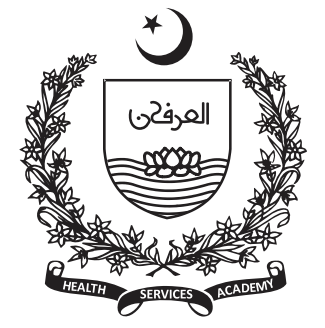

\title{
Tracking Pakistan's Progress Towards Universal Health Coverage: An Empirical Assessment of Summary and Tracer Indicators and Their Associated Inequities (2001-14)
}

\author{
Faraz Khalid1', Abdul Sattar 2, Maria Petro Brunal', Wajeeha Raza4,
} David Hotchkiss ${ }^{5}$

\section{${ }^{1} \mathrm{PhD}$, Health Systems Department, World Health Organization, Eastern Mediterranean Regional Office \\ 2 PhD, World Food Program, Islamabad, Pakistan}

${ }^{3} \mathrm{MSc}$, The Global Fund to Fight AIDS, Tuberculosis and Malaria, Geneva, Switzerland

${ }^{4}$ MHS, Agha Khan University, Karachi, Pakistan

${ }^{5}$ PhD, Tulane University School of Public Health \& Tropical Medicine

Corresponding Author: Faraz Khalid

Email:

dr.faraz1982@gmail.com

\section{Abstract}

Background: This study's main objective was to examine the progress of provinces towards UHC using several tracer indicators (six for health service coverage and two for financial protection) from 2001 to 2014 and to assess inequities within provinces due to place of residence and economic status.

Methods: For elaborate tracking, inequities were assessed for each indicator based on average annual rates of change and percentage changes in the gap between sub-population groups. For policy makers, spider radar graphs were generated to demonstrate UHC status in 2014, and a composite UHC index was created to show trends from 2001-14. Four Household Integrated Economic Survey data sets (2001-02, 2004-05, 2010-11, 2013-14), each with a sample size of about 15,000 households, were used for the analysis.

Results: Overall, all four provinces made progress in their UHC index values over the study period. Coverage for most of treatment indicators remained below $70 \%$ and inequities existed among sub-population groups. Coverage of financial protection indicators remained above $90 \%$ for all the provinces across study duration and no substantial differences were found between and within provinces.

Conclusion: Simultaneous monitoring of both dimensions of UHC enabled the authors to comment on the holistic picture of UHC status and data blind spots, and to avoid inappropriate interpretations about a single dimension. Higher level of financial protection with limited health services coverage was most likely due to non-utilization of health services and/or unmet health needs. The findings will likely serve as a baseline for tracking progress towards UHC at the sub-national level in the country.

Keywords: Universal health coverage, Pakistan, equity, health systems, monitoring 


\section{Introduction}

$\mathrm{U}$ niversal Health Coverage (UHC) means that everyone can receive the quality essential health services that they need without enduring financial hardship at the time of obtaining care(1). In 2012, UHC was declared as one of the targets for the Sustainable Development Goals 2030(2), and since then, more than 100 low- and middleincome countries, housing three-fourth of the world's population, have initiated UHC reforms. (3)

In 2015, the World Health Organization (WHO) and The World Bank in the PLOS Collection's special issue "Monitoring Universal Health Coverage", presented the first regional and national comparison of measuring UHC in "Tracking Universal Health Coverage - First Global Monitoring Report". The report recommended monitoring both dimensions of UHC at the country level - health service coverage and financial protection, side by side regularly and suggested eight core tracer health service coverage and two financial protection indictors. A strong emphasis was laid on monitoring inequities within countries; geographical location, wealth status, gender, and age were the most cited types of inequities.

In Pakistan, a lower middle-income country in South Asia with a population of over than 220 million (4), health indicators have improved over the last 70 years, but they still lag behind internationally agreedupon targets. The federal and provincial health ministries, have recently committed to make UHC a reality for their citizens by signing the National Health Vision 2016-25 (5). Since health is a provincial government mandate following passage of the $18^{\text {th }}$ constitutional amendment, monitoring and reporting progress towards Sustainable Development Goal (SDG) 3 at the provincial level has been identified as one of key areas for future deliberations. However, there are challenges to tracking progress. A preliminary assessment conducted to examine the data gaps has revealed that there is scarce data available for SDG 3 monitoring both at the federal and provincial levels(6). Pakistan does have a few surveys which capture health service coverage indicators (7-9) and health expenditures (10) over the last 15 years, however, no study has comprehensively captured both dimensions of UHC simultaneously to give a complete picture of UHC status at the provincial level in the country.
Drawing guidance from "Tracking Universal Health Coverage - First Global Monitoring Report" of 2015(3), this study assessed UHC status at the subnational (provincial) level, and explored inequities within provinces due to place of residence and economic status. Furthermore, this study examined the progress at the provincial level for the tracer health service and financial protection coverage indicators from 2001 to 2014, created a composite UHC index, and identified the data blind spots. In addition to the Ministry of Health, the Federal Bureau of Statistics, and health financing practitioners, this research will be of interest to the SDG secretariat in the parliament and SDG support units in the federal and provincial governments, who will be able to use this study's results as a baseline for tracking progress towards UHC.

\section{Methodology}

Four Household Integrated Economic Survey (HIES) data sets (2001-02, 2004-05, 2010-11, and 201314) were used for this analysis. There were several reasons for selecting the HIES for this study: first, the same instrument, with minor modifications, was used from 2001 to 2014; second, the data was both nationally and provincially representative and reported six targets and 13 indicators related to UHC monitoring, including indicators for immunization, diarrhea, antenatal and post-natal care, deliveries, access to improved drinking water and sanitation. Lastly, the survey also collected information on household size, employment status, sources of income, and consumption expenditures, including health expenditures. Thus, with HIES, tracer indictors for both health service coverage and financial protection could be estimated from 2001 to 2014 with the same questionnaire administered on nationally/provincially representation samples.

HIES 2001-02 was part of the Pakistan Integrated Household Survey 2001-02 and the HIES 2004-05, 2010-11, and 2013-14 were conducted as part of the Pakistan Social and Living Standards Measurement (PSLM) Surveys Project(11). For each survey, the sample size was around 15,000 households using a multi-stage sampling technique; sampling weights for national representation were available. The universe of each survey consisted of all urban and rural areas of all four provinces, as defined by the respective provincial governments. 


\section{Method of Analyses}

Analyses were done to generate both concise and elaborate results. For policy makers, results were presented through spider radar graphs to show the UHC status in 2014, and through a UHC index to show the trends from 2001-14. For elaborate tracking of UHC progress, inequities were assessed for each indicator at the provincial level. All the analyses were done using Stata version 12.

\section{Measures/Indicators}

Guidance was sought from "Tracking Universal Health Coverage - First Global Monitoring Report"2015 (3) for selecting tracer indicators related to both dimensions of UHC. Though HIES did not have the data needed for all the recommended health service coverage tracer indicators, we were able to identify six health service coverage indicators (three each for preventive and treatment) chosen by Government of Pakistan for monitoring the country's progress towards the MDGs, as the tracer indicators. The modes of estimation of all the indicators are described in Table 1.

Table I. Health service coverage and financial protection tracer indicators

\begin{tabular}{|l|l|}
\hline Concept & Indicator \\
\hline $\begin{array}{l}\text { Immunization coverage } \\
\text { for Diphtheria Pertussis } \\
\text { Tetanus (DPT) }\end{array}$ & $\begin{array}{l}\text { Percentage of children } \\
\text { aged 12-23 months that } \\
\text { have received 3 doses of } \\
\text { DPT (based on record and } \\
\text { recall). }\end{array}$ \\
\hline Prenatal care coverage & $\begin{array}{l}\text { Percentage of ever married } \\
\text { women aged 15 - 49 years } \\
\text { who had given birth in the } \\
\text { last three years and who } \\
\text { had attended at least one } \\
\text { pre-natal consultation } \\
\text { during the last pregnancy. }\end{array}$ \\
\hline Postnatal care coverage & $\begin{array}{l}\text { Percentage of ever married } \\
\text { women aged 15-49 years } \\
\text { who had a birth in the past } \\
\text { three years who received } \\
\text { post-natal check-up within } \\
6 \text { weeks after delivery. }\end{array}$ \\
\hline $\begin{array}{l}\text { Skilled } \\
\text { assistance }\end{array}$ & $\begin{array}{l}\text { Percentage of live births to } \\
\text { all ever-married women } \\
\text { aged 15-49 years during } \\
\text { the past three years (last } \\
\text { pregnancy only) that were }\end{array}$ \\
\hline
\end{tabular}

\begin{tabular}{|c|c|}
\hline & $\begin{array}{lcc}\text { attended } & \text { by } & \text { skilled } \\
\text { provider (doctor, } & \text { nurse, } \\
\text { midwife, lady health } \\
\text { visitor, and lady } & \text { health } \\
\text { worker). } & & \\
\end{array}$ \\
\hline $\begin{array}{l}\text { Treatment of child } \\
\text { diarrhea with ORS }\end{array}$ & $\begin{array}{l}\text { Percentage of children less } \\
\text { than } 5 \text { years that were } \\
\text { reported to have an } \\
\text { episode of diarrhea in the } \\
\text { past } 30 \text { days who were } \\
\text { given ORS. }\end{array}$ \\
\hline $\begin{array}{l}\text { Usage of improved } \\
\text { sanitation facilities }\end{array}$ & $\begin{array}{l}\text { Percentage of population } \\
\text { using improved sanitation } \\
\text { facilities ((flush connected } \\
\text { to public sewerage, pit or } \\
\text { open drain) }\end{array}$ \\
\hline $\begin{array}{l}\text { Catastrophic health } \\
\text { expenditures }\end{array}$ & $\begin{array}{l}\text { Percentage of households } \\
\text { spending } 40 \% \text { or more of } \\
\text { their capacity to pay on } \\
\text { out of pocket expenditures } \\
\text { for health (1). } \\
\text { Capacity to pay (CTP) is } \\
\text { defined as the difference } \\
\text { between total household } \\
\text { expenditure and } \\
\text { subsistence food } \\
\text { expenditure. } \\
\text { "Subsistence level of food } \\
\text { expenditure is estimated as } \\
\text { the average food expenditure } \\
\text { per equivalent adults of } \\
\text { households in the 45th-55th } \\
\text { food budget share } \\
\text { distribution.5 When actual } \\
\text { food spending falls below this } \\
\text { amount, then capacity to pay } \\
\text { is defined as total } \\
\text { expenditures net of actual } \\
\text { food spending. This also } \\
\text { avoids estimating a negative } \\
\text { level of capacity to pay." (2) }\end{array}$ \\
\hline $\begin{array}{l}\text { Impoverishing health } \\
\text { expenditures }\end{array}$ & $\begin{array}{l}\text { Percentage of households } \\
\text { with total household } \\
\text { expenditure gross of out of } \\
\text { pocket expenditure on } \\
\text { health above the amount } \\
\text { equivalent to subsistence } \\
\text { food expenditures but with } \\
\text { total household } \\
\text { expenditure net of out of } \\
\text { pocket expenditure on } \\
\text { health below the amount } \\
\text { equivalent to subsistence } \\
\text { food expenditures (14) }\end{array}$ \\
\hline
\end{tabular}

Pak J Public Health; Vol 10(1): March 2020 
Tracking Pakistan's Progress Towards Universal Health Coverage: An Empirical Assessment of Summary and Tracer Indicators and Their Associated Inequities (2001-14)

\section{UHC status in 2014}

The latest data set available for this analysis was from 2014. Spider radar graphs were used to illustrate UHC status in 2014 at the sub-national (provincial) level. Each graph captures six health service coverage and two financial protection indicators. Each of the indicators represented an axis in the spider web, with the centre representing zero coverage and the outer edge denoting full (100\%) coverage. Five quantiles, reflecting economic status, were based on household expenditures. Differences in coverage between the richest and the poorest, and rural and urban households, are shown to demonstrate inequities within provinces.

\section{UHC index and its trend (2001-14)}

Guidance was drawn from the seminal World Bank publication "Measuring progress towards universal health coverage: with an application to 24 developing countries" to develop a UHC index relevant for Pakistan (12). We followed the methodology adopted by Wagstaff et al in the aforementioned publication to assign equal 50\% weights to health service coverage and financial protection indicators, which is expected to make it easier for policy makers to understand and compare the two indicators (12). However, all the health service coverage indicators were not available in Pakistan. So, with the available indicators, a UHC index was created to compare the progress of provinces from 2001 to 2014. The weights assigned to each indicator can be found in Annexe 1 .

\section{Progress and inequities in health service coverage and financial protection indicators from 2001-14}

Average annual rate of change for each indicator was estimated by subtracting the coverage percentage/incidence in 2001-02 from that of 2013-14 and then dividing the total change by 13 (number of years). A provincial breakdown can be found in Annexe 2

Percentage change in coverage gap/incidence gap between the poorest and richest was estimated by first calculating the gap between the two groups in both 2001-02 and 2013-14 separately, and then by subtracting the gap in 2001-02 from that of 2013-14. A similar approach was adopted for estimating the percentage change in coverage gap/incidence gap between rural and urban households. A provincial breakdown can be found in Annexe 2

\section{Results}

\section{UHC status in 2014}

Spider radar graphs in Figure 1 depict comparisons between provinces by their UHC status in 2014. Our analysis finds large differences across provinces for health service coverage indicators but not for financial protection indicators. Spider radar graphs in Figure 2 show comparisons for UHC status within each of the provinces; there were marked differences between urban and rural areas, and the richest and poorest within all the provinces. Though service coverage indicators were lower for the poorest and rural households, the gap between financial protection indicators between richest and poorest, urban and rural, was not as wide.
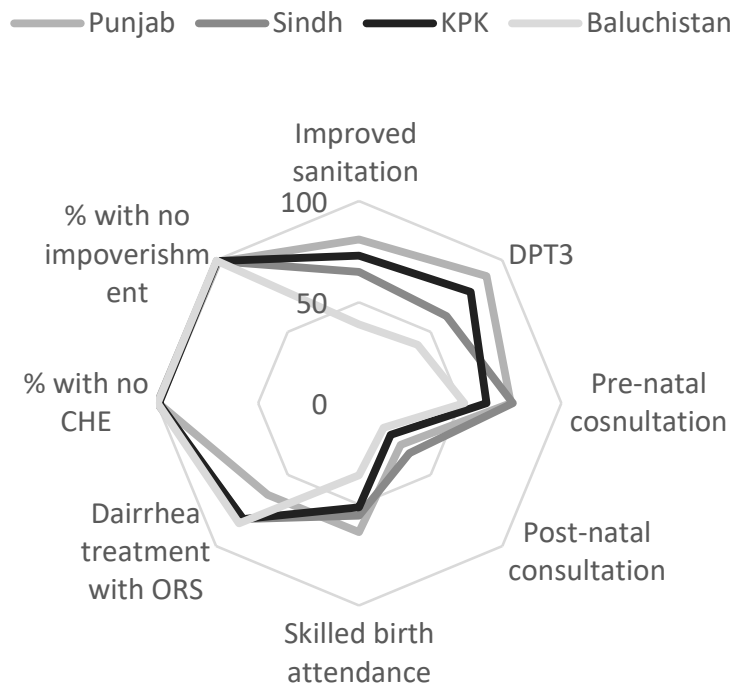

Figure 1. UHC status in 2014 - Inequities between Provinces 


\section{Punjab}

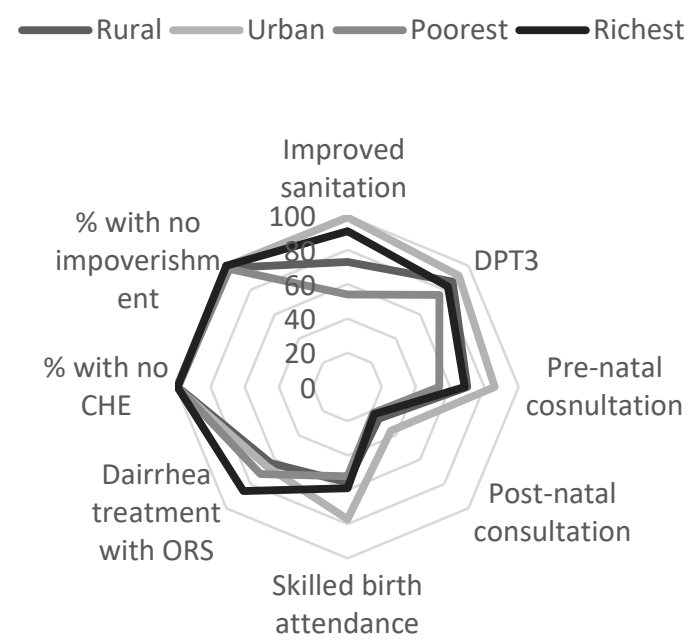

\section{Sindh}
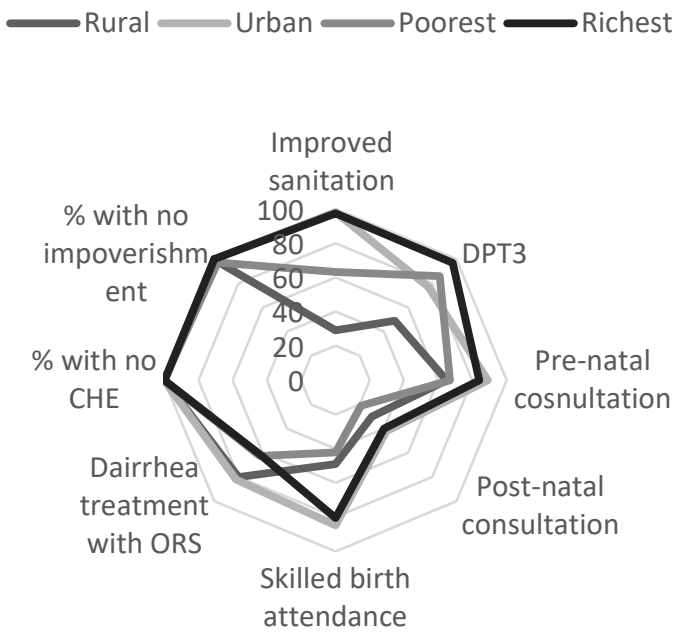
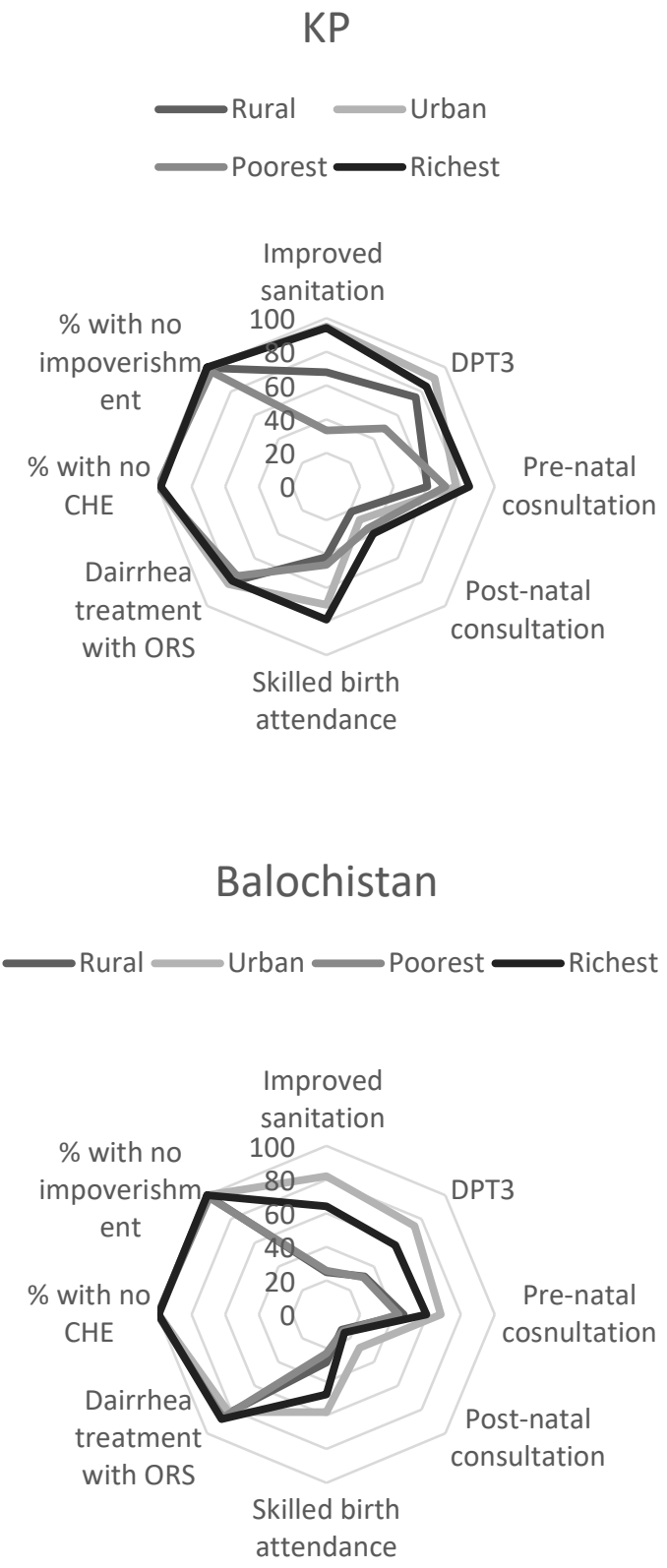

Figure 2. UHC status in 2014 - Inequities within Provinces 


\section{UHC index trend (2001-14)}

The UHC index trend and its values are shown in Figure 3. Calculations done for estimating UHC index are presented in Annex 1. Overall, all provinces made progress in their index values over the study period. Sindh had the highest index value throughout the study period, while Balochistan had the lowest value for all thirteen years.

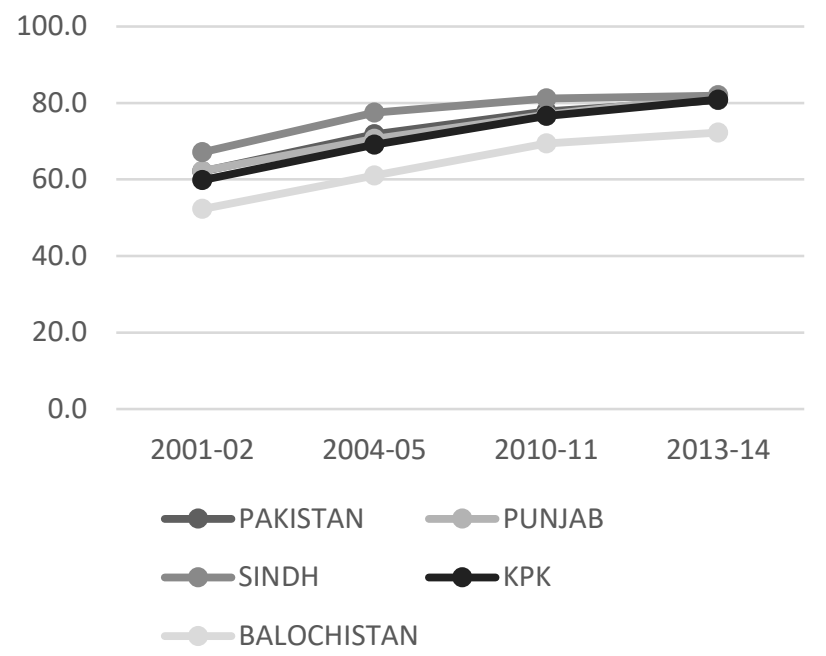

Figure 3. UHC Index - National and Provincial Trends 2001-14

Progress and inequities in health service coverage and financial protection indicators (2001-14)

Estimations for the all the indicators, along with their rural/urban and economic quintiles disaggregation for each of the four survey years are presented in Annex 3, while provincial breakdowns for annual rate of change further disaggregated by urban/rural and richest/poorest are presented in Annexe 2. A summary of the results at the provincial level is presented below

\section{Punjab}

As shown in Annexe 2a, the gap between rural and urban households for the coverage of four health service indicators reduced in 13 years in Punjab. However, there is still substantial inequity between urban and rural Punjab as by 2014, coverage of three health service indicators crossed $80 \%$ for urban, but coverage of only one health service indicator was more than $80 \%$ for the rural. On the financial protection measures, more than $90 \%$ of households did not incur financial risk for both urban and rural groups in 2014.

By 2014, coverage of three out of six health service indicators crossed $80 \%$ for the richest, but none of the health service indicators was more than $80 \%$ for the poorest. Our analysis also finds more than $85 \%$ poorest and more than $95 \%$ richest were financially protected in 2014. The gap between both poorest and richest for both financial protection indicators increased in 13 years.

Sindh

Annexe $2 b$ outlines the progress and inequities for UHC tracer indicators for the Sindh province. Similar to the progress in other provinces, the gap between rural and urban households for five health service coverage indicators has decreased in Sindh. However, despite improvements in most service coverage indicators for rural Sindh, the coverage statistics for 2014 shows significant geographic inequities as urban households had more than $80 \%$ coverage for four, and rural households had $80 \%$ coverage for only one health service coverage indictor. More than $95 \%$ of households were financially protected among both urban and rural groups in 2014. The gap between rural and urban households for both financial protection indicators decreased in13 years.

More than $90 \%$ poorest and more than $95 \%$ richest were financially protected in 2014. The gap between poorest and richest for both financial protection indicators decreased in Sindh over the 13-year study period.

\section{Khyber Pakhtunkhwa}

Annexe 2c outlines the progress and inequities for $\mathrm{UHC}$ tracer indicators for the KP province. In KP, the gap between rural and urban households shows a decrease for three out of six health service coverage indicators between 2001-02 to 2013-14. By 2014, coverage of three health service indicators was more than $80 \%$ for the urban households, but for the rural, only one health service indicator had $80 \%$ coverage. More than 95\% households in both urban and rural groups had financial protection in 2014; the gap between rural and urban households was reduced for both financial protection indicators in 13 years.

$\mathrm{KP}$ has slower progress on reducing inequity between income groups as the gap between poorest and richest households for coverage of only one health service indicator was reduced by more than $1 \%$ in 13 
years. Overall statistics for KP also show significant disparities between economic groups as by 2014, coverage of five health service indicators was either close to or had crossed $80 \%$ for the richest, but coverage of none of the health service indicators was more than $80 \%$ for the poorest. However, around $90 \%$ poorest and more than $95 \%$ richest were financially protected in 2014. The gap between poorest and richest for both financial protection indicators decreased in 13 years.

\section{Balochistan}

Annexe $2 \mathrm{~d}$ outlines the progress and inequities for UHC tracer indicators for the Balochistan province. Balochistan has the lowest progress in reducing geographic inequities in health service coverage, as the gap between rural and urban households decreased for only two health service coverage indicators. Overall, coverage of health service indicators has been the lowest for Balochistan and by 2014, coverage of only two health service indicators was more than $80 \%$ for the urban households, and coverage of one health service indicator was more $80 \%$ for rural households. However, more than $95 \%$ households in both urban and rural groups had financial protection in 2014; the gap between rural and urban households was reduced for one financial protection indicator in 13 years.

The gap between poorest and richest households shows limited improvement in Balochistan, and by 2014, coverage of one health service indicator crossed $80 \%$ for both of the richest and poorest groups. Balochistan has the highest financial protection among the four provinces, measured as more than 95\% households in both poorest and richest groups were financially protected in 2014. The gap between poorest and richest for both financial protection indicators decreased in 13 years.

\section{Discussion}

Globally, UHC progress was initially assessed and tracked only at the national level (13). This approach has some limitations as it can hide the underlying variations between geographical divisions and sub-populations in a country (3). Moreover, many UHC programs now have state/province/district level variations in their design. This makes it imperative for countries to regularly track their progress both at the national and sub-national levels. This study fills this gap in monitoring UHC for Pakistan by assessing and comparing the progress for
UHC between all the provinces and within the provinces on two important equity dimensions for over a 13-year period, and can serve as an example for other countries to follow.

Overall, there has been improvement in coverage of all the indicators. Among the health service coverage indicators, greater improvements were observed for prevention in comparison with treatment. The findings corroborate with the results published by Planning Commission, Government of Pakistan (14). Further research needs to be undertaken at the provincial level to assess the reasons for differential progress on prevention and treatment indicators, and particularly the specific tracer indicators related to the same program.

Among the financial protection indicators, results across the 13-year time span in all four provinces reveal a low percentage of households with catastrophic health expenditure and impoverishment. However, it is important to interpret these results together with the service coverage indicators. For example, if we look at the province Balochistan, where both financial risk protection indicators had more than $95 \%$ coverage even for poorest and rural groups in 2001, the corresponding health service coverage indicators other than the indicator for treatment of diarrhoea with ORS, all had values of less than $60 \%$ coverage. Thus, the likely reason for the finding of a high level of financial protection was not that Pakistan had a very responsive health system with extended coverage of health services, but the result of a high level of forgone care. This point was further explicitly highlighted in the spider radar graphs depicting the UHC status in 2014. There were substantial differences between and within provinces for the health service coverage indicators, but not for financial protection indicators; higher level of financial protection with minimal health services coverage was probably because of non-utilization of health services and/or unmet health needs.

There are three main limitations with the data that should be noted. First was related to the selected tracer indicators; the health service coverage indictors were MDG related, and they certainly do not give the complete picture of Universal Health Coverage status at the provincial level, particularly as they miss out on indicators related to non-communicable diseases (NCDs). Household Integrated Economic Surveys captured health expenditures in 2-4 questions and non-medical expenditures were solicited in more than 
150 questions in each survey. Thus, there is a probability of under-reporting of medical expenditures in these surveys, resulting in overestimation of financial protection status of the provinces.

A second limitation was the lack of data for estimating effective coverage - encompassing quality of services and impact of services on health of populations. For this, there was no corresponding health facility data that could be linked to the household level surveys used.

Lastly, our analysis on tracking UHC progress in Pakistan was conducted using guidelines from the first global monitoring report for tracking UHC. Since then, a new report on tracking UHC has been published in 2017, which may serve as an important resource for further research on tracking UHC in Pakistan. The major variations in the 2017 report are the computation of a UHC service coverage index, and the thresholds used to measure catastrophic health expenditures (World Health Organization). There is no one size fits all approach to achieving or measuring UHC and questions on which indicators and formula to use are currently left at the country's discretion, which may serve as an additional area for further research.

\section{Conclusion}

A provincial level tracking of universal health coverage with dis-aggregated information on two equity dimensions for a 13-year time span signals that Pakistan already has a foundation of health indicators and a capital of experience in collating data for the MDGs. Now, as the SDGs have been endorsed by National assembly as National Development agenda and federal and provincial governments have committed to UHC reforms, it is imperative for the SDGs secretariats to effectively track UHC both at the national and provincial levels. This cannot happen without strengthening and integrating the existing health information systems in the country. There is a dire need to include indicators for NCDs and injuries in the existing household surveys, map out the existing number and distribution of health facilities and health workers in public and private sectors, include quality of care indicators in the health facility data, and to consolidate the information being collected from health facilities with household surveys. Without this, it will not be possible for policy makers to gauge the direction and progress of UHC reforms. Further, health financing practitioners need to track financial protection and health service coverage indicators simultaneously and should regularly assess the differential effects of the UHC schemes on sub-populations groups to ensure that the recently launched reforms reduce inequities in the country.

\section{Acknowledgements}

The authors are thankful to Valerie A Yeager and Samia Laokri for providing useful suggestions during development of this paper.

\section{References}

1. World Health Organisation. World Health Report, 2010: Health Systems Financing: The Path to Universal Coverage. Geneva: World Health Organization; 2010. Contract No.: Report.[Available at: https://www.who.int/whr/2010/en/]

2. World Health Organisation. Health in 2015: from MDGs Millennium Development Goals to SDGs Sustainable Development Goals. Geneva: World Health Organization; 2015.[Available at: https://www.who.int/gho/publications/mdgssdgs/en/]

3. World Health Organisation, World Bank G. Tracking universal health coverage: first global monitoring report. France: World Health Organization; 2015. Contract No.: Report. [Available at: https://apps.who.int/iris/bitstream/handle/10665/17 4536/9789241564977_eng.pdf?sequence=1]

4. Pakistan Bureau of Statistics GoP. Population Census 2017 [Available at: http://www.pbs.gov.pk/content/population-census]

5. Ministry of National Health Services Regulation and Coordination. National Health Vision Pakistan 20162025. Islamabad: Ministry of National Health Services, Regulation and Coordination, Government of Pakistan; 2016. Contract No.: Report. [Available at: http://www.nationalplanningcycles.org/sites/default/ files/planning_cycle_repository/pakistan/national_hea lth_vision_2016-25_30-08-2016.pdf]

6. United Nations Development Goals. The sustainable development goals are coming to life - stories of country implementation and UN support. United States of America: United Nations Development Group; 2016. [Available at: https://www.undp.org/content/undp/en/home/libra rypage/sustainable-development-goals/thesustainable-development-goals-are-coming-to-life.html]

7. Pakistan Bureau of Statistics GoP. Pakistan Social and Living Standards Measurement Survey (2014-15). Islamabad: Pakistan Bureau of Statistics Government of Pakistan; 2016. Report No.: 2018 Contract No.: 05/13. 
[Available

http://www pbs.gov pk lications/PSLM_2014-15_National-Provincial-

District_report.pdf]

8. United Nations International Children's Emergency Fund. Multiple Indicator Cluster Survey: United Nations International Children's Emergency Fund; [Available from: http://mics.unicef.org/news_entries/23.

9. National Institute of Population Studies Pakistan, International ICF. Pakistan Demographic and Health Survey 2012-13. Islamabad, Pakistan, and Calverton, Maryland: NIPS and ICF International; 2013. Report No.: $2016 \quad$ Contract $\quad$ No.: $10 / 9$. [https://www.nips.org.pk/abstract_files/PDHS\%20Fin al\%20Report \%20as\%20of\%20Jan \%2022-2014.pdf]

10. Pakistan Bureau of Statistics GoP. Pakistan National Health Accounts 2013-14. Islamabad: Pakistan Bureau of Statistics, Government of Pakistan; 2016. Contract No.: Report.
11. Pakistan Bureau of Statistics GoP. Household Integrated Economic Survey (HIES) 2011-12. Pakistan Bureau of Statistics, Government of Pakistan; 2013. Contract No.: Report.[Available

at: http://www.pbs.gov.pk/content/householdintegrated-economic-survey-hies-2011-12]

12. Wagstaff A, Cotlear D, Eozenou PH-V, Buisman LR. Measuring progress towards universal health coverage: with an application to 24 developing countries. Oxford Review of Economic Policy. 2016;32(1):147. [Available at: https:/ /doi.org/10.1093/oxrep/grv019]

13. World Health Organisation, The World B. PLOS Collections: Monitoring Universal Health Coverage PLOS; 2014 [Available from: http://collections.plos.org/uhc2014.

14. Planning Commission GoP. Pakistan Millenium Development Goals Report 2013. Islamabad, Pakistan: Ministry of Planning, Development and Reform, Government of Pakistan; 2013. Contract No.: Report. 